\title{
COVID-19 in cancer patients: clinical characteristics and outcome-an analysis of the LEOSS registry
}

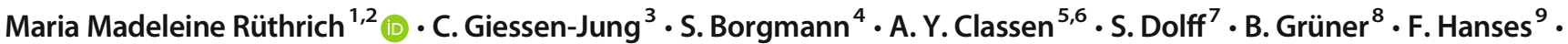 \\ N. Isberner ${ }^{10}$ • P. Köhler ${ }^{11}$ • J. Lanznaster ${ }^{12} \cdot$ U. Merle ${ }^{13} \cdot$ S. Nadalin ${ }^{14} \cdot$ C. Piepel ${ }^{15}$ - J. Schneider ${ }^{16,17} \cdot$ M. Schons ${ }^{5}$.

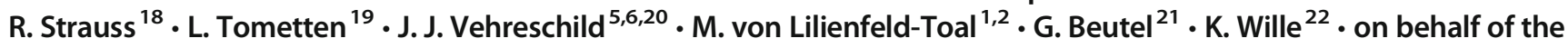 \\ LEOSS Study Group
}

Received: 12 October 2020 / Accepted: 27 October 2020 / Published online: 7 November 2020

(C) The Author(s) 2020

\begin{abstract}
Introduction Since the early SARS-CoV-2 pandemic, cancer patients have been assumed to be at higher risk for severe COVID19. Here, we present an analysis of cancer patients from the LEOSS (Lean European Open Survey on SARS-CoV-2 Infected Patients) registry to determine whether cancer patients are at higher risk.

Patients and methods We retrospectively analyzed a cohort of 435 cancer patients and 2636 non-cancer patients with confirmed SARS-CoV-2 infection, enrolled between March 16 and August 31, 2020. Data on socio-demographics, comorbidities, cancerrelated features and infection course were collected. Age-, sex- and comorbidity-adjusted analysis was performed. Primary endpoint was COVID-19-related mortality.

Results In total, 435 cancer patients were included in our analysis. Commonest age category was $76-85$ years (36.5\%), and $40.5 \%$ were female. Solid tumors were seen in $59 \%$ and lymphoma and leukemia in $17.5 \%$ and $11 \%$ of patients. Of these, $54 \%$ had an active malignancy, and $22 \%$ had recently received anti-cancer treatments. At detection of SARS-CoV-2, the majority $(62.5 \%)$ presented with mild symptoms. Progression to severe COVID-19 was seen in 55\% and ICU admission in $27.5 \%$. COVID-19-related mortality rate was $22.5 \%$. Male sex, advanced age, and active malignancy were associated with higher death rates. Comparing cancer and non-cancer patients, age distribution and comorbidity differed significantly, as did mortality ( $14 \%$ vs $22.5 \%, p$ value $<0.001)$. After adjustments for other risk factors, mortality was comparable.

Conclusion Comparing cancer and non-cancer patients, outcome of COVID-19 was comparable after adjusting for age, sex, and comorbidity. However, our results emphasize that cancer patients as a group are at higher risk due to advanced age and preexisting conditions.
\end{abstract}

Keywords COVID-19 $\cdot$ SARS-CoV-2 $\cdot$ Cancer patients $\cdot$ Pandemic $\cdot$ LEOSS $\cdot$ Cohort study $\cdot$ Adjusted analysis

\section{Introduction}

Since the emergence of severe acute respiratory syndrome coronavirus 2 (SARS-CoV-2) in December 2019 in Wuhan, global

This study is registered at the German Clinical Trials Register (DRSK, S00021145). Date of registration: 08.04.2020

Supplementary Information The online version contains supplementary material available at https://doi.org/10.1007/s00277-02004328-4.

Maria Madeleine Rüthrich

maria.ruethrich@med.uni-jena.de

Extended author information available on the last page of the article number of coronavirus disease 2019 (COVID-19) cases are steadily increasing [1]. As of October 12, 2020, approximately 4.1 million cases and 195,650 deaths related to COVID-19 have been reported in the EU/EEA and the UK [2].

In COVID-19, clinical findings can range from mild flu-like symptoms to life-threatening respiratory insufficiency. Average incubation period is 5-6 days, while the period between infection onset to hospitalization is reported as 7 , to respiratory deterioration 8 , and to ICU admission 10 days [3, 4]. Although cancer and noncancer patients appear to have similar infection rates, it is generally assumed that cancer patients are at higher risk for severe COVID-19 and death attributed to COVID-19 [5-8]. Numerous studies identified advanced age, male sex, and a high number of comorbidities as 
risk factors for a worse outcome [6, 9-11]. Additionally, cancer-related features, such as immunodeficiency due to the underlying malignancy, effects of anti-cancer therapies, and frequent contacts with healthcare workers are discussed being associated with higher mortality and severe infection course [9, 12, 13].

Although detailed descriptions and analyses of risk factors, clinical courses, and mortality in cancer patients infected with SARS-CoV-2 exist, published literature is heterogeneous regarding tumor entities, anti-cancer treatment and matched confounders [5, 9, 12-15]. Moreover, comparisons of cancer and non-cancer patients are scarce.

Here, we present an analysis of SARS-CoV-2-infected cancer patients from the Lean European Open Survey on SARSCoV-2 (LEOSS) registry. We aimed to describe epidemiological and clinical features and to determine whether cancer patients are at higher risk for severe infection course and COVID-19 mortality compared to non-cancer patients.

\section{Patients and methods}

In March 2020, the multicenter Lean European Open Survey on SARS-CoV-2 infected patients (LEOSS) registry was established in order to quickly gain knowledge about the epidemiology and clinical course of patients infected with SARS-CoV-2.

We retrospectively assessed the data of cancer patients and a non-cancer control cohort with (PCR) confirmed SARSCoV-2 infection, who were hospitalized or treated in an outpatient setting at a LEOSS partner site. From a total of 3071 patients, enrolled between March 16 and August 31 2020, 435 cancer patients could be identified. Only patients with available data on follow-up or last known status were included. Baseline patients' data were collected on socio-demographics, the presence of comorbidity according to Charlson Comorbidity Index (CCI), and cancer-related features, including entity, Eastern Cooperative Oncology Group Index (ECOG), disease status at detection of SARS-CoV-2 (active disease, chemotherapy, high-dose steroids, targeted therapy, other immunosuppressive medication, remission) and information about the anti-cancer therapy. Unfortunately, information on causative treatment of COVID-19 from this early phase of the pandemic was not available in a systematic and controlled fashion. We therefore did not include any analysis on putative therapeutic effects.

Clinical manifestation of COVID-19 was described in four phases: uncomplicated (oligo-/asymptomatic), complicated (need for oxygen supplementation), critical (need for life supporting therapy), and recovery (clinical improvement/discharge, Table 1). Symptoms, vital signs, and laboratory values were analyzed over all phases as was outcome of SARS-CoV2 infection. Primary endpoint was death attributed to COVID19. Secondary endpoints were survival at day 30 and outcome from SARS-CoV-2 infection after adjustments for age, sex, and comorbidity.

\section{Data collection and statistical analysis}

Anonymized data was collected in an electronic case report form (eCRF) using the online platform ClinicalSurveys.net, which was developed by the University Hospital of Cologne (UHC). Data management and statistical analysis was performed with SPSS software version 27.0 (IBM, Corp. in Armonk, NY). Categorical variables were expressed using counts and percentages. Continuous data were presented as mean with standard deviation $( \pm \mathrm{SD})$ or as median with interquartile range (IQR). To compare categorical variables, Pearson's chi-square test was used. Two-sided $t$ test was used to compare continuous data. Survival was

Table 1 LEOSS clinical phases

\begin{tabular}{|c|c|}
\hline Uncomplicated phase & Recovery phase \\
\hline - Asymptomatic OR & $\begin{array}{l}\text { - Improvement by one degree of severity according scheme } \\
\text { of LEOSS clinical phases or discharge AND }\end{array}$ \\
\hline - Gastrointestinal symptoms & - Defervescence AND \\
\hline - Fever & - No progression/re-hospitalization \\
\hline Complicated phase & Critical phase \\
\hline - Need for oxygen supplementation & - Need for catecholamines \\
\hline - Increase of prior oxygen home therapy & - Life-threatening cardiac arrhythmia \\
\hline - $\mathrm{paO} 2<70 \mathrm{mmHg} / \mathrm{SO} 2<90 \%$ (at room air) & - Need for unplanned mechanical ventilation \\
\hline - Transaminases $>5 \times$ ULN & - Prolongation of planned mechanical ventilation \\
\hline - New cardiac arrhythmia & - Liver failure (Quick < 50\%) \\
\hline - New pericardial effusion $(>1 \mathrm{~cm})$ & - $\mathrm{qSOFA} \geq 2$ \\
\hline $\begin{array}{l}\text { - New heart failure with pulmonary edema, } \\
\text { congestive hepatopathy, peripheral edema }\end{array}$ & - Acute renal failure in need of dialysis \\
\hline
\end{tabular}


estimated using the Kaplan-Meier method (log-rank test). Patients were adjusted for age, sex, and comorbidity. Significance level was set at 0.05 .

\section{Results}

\section{Baseline characteristics}

A total of 435 cancer patients with SARS-CoV-2 infection treated at a LEOSS study site were included in our analysis. The majority of patients were hospitalized (98\%, 427/435). Detailed patients' characteristics are shown in Table 2. Median observational period was 14 days (IQR 7 - 24) and median duration of hospitalization 15 days (IQR $8-27.5$ ). More men than women were included $(59.5 \%$ vs $40.5 \%)$. Most common age category was $76-85$ (36.5\%). A male predominance was seen across all age categories except for patients $>85$ years (female 19/38 vs male 19/38). In 23.5\% (44/ 187), ECOG was $>2$. Mean CCI was 4.64 , while common comorbidities taken into account were chronic kidney disease and cardiovascular diseases. Arterial hypertension was seen in $60 \%$. Solid tumors were documented for $256(59 \%)$ and lymphoma and leukemia for $76(17.5 \%)$ and $48(11 \%)$ patients, respectively. Common solid tumor entities were gastrointestinal cancer $(14 \%, 60 / 421)$, lung cancer $(8.5 \%, 36 / 421)$, gynecological and breast cancer $(9 \%, 39 / 421$ and 9.5\%, 21/421, respectively). Metastasized solid tumors were seen in 95 $(22 \%, 95 / 435)$ patients. Commonest hematological malignancies were non-Hodgkin lymphoma $(16.5 \%, 71 / 421)$ and acute myeloid leukemia $(3 \%, 14 / 421)$. About half of patients had an active malignancy at detection of SARS-CoV-2, one-quarter had received anti-cancer treatments within the last 3 months. Type of therapy was almost equally distributed between chemotherapy, radiation, and surgery.

\section{Clinical course of COVID-19}

At the time of a positive test for SARS-CoV-2, 272 (63\%) patients were in an uncomplicated phase (according to LEOSS clinical stages, suppl. Table 1). Most common symptoms were fever $(34 \%, 148 / 398)$, dry cough $(24.5 \%, 106 / 398)$, dyspnea $(23.9 \%, 104 / 379)$, and excessive tiredness $(18.9 \%, 82 / 398)$. Fifty-eight $(13.5 \%, 58 / 398)$ patients were reported to be asymptomatic. Signs of advanced stages were described in a minority of patients: oxygen saturation $<90 \%$ in $15.5 \%$, systolic blood pressure $<80 \mathrm{mmHg}$ in $0.5 \%$, diastolic blood pressure $<60 \mathrm{mmHg}$ in $12.5 \%$, and heart rate $\geq$ $90 \mathrm{bpm}$ in $35.5 \%$ of the patients. Anemia was reported in $56 \%$ and lymphopenia and neutropenia in $83.5 \%$ and $18 \%$, respectively. C-reactive protein (CRP) was above $120 \mathrm{mg} / \mathrm{L}$ in $66(18.5 \%)$ patients.
Progression to complicated or critical phases were observed in $206(55 \%, 206 / 376)$ patients. One-hundred and nineteen $(27.5 \%, 119 / 435)$ patients were admitted to ICU with $78(65.5 \%, 78 / 119)$ patients receiving mechanical ventilation. Median ICU length of stay was 11 days (IQR $7.75-27$ ). Along with progression to the critical phase, oxygen saturation decreased below $90 \%$ in $79 \%$, while systolic blood pressure less than $80 \mathrm{mmHg}$ and diastolic blood pressure less than $60 \mathrm{mmHg}$ were found in $30.5 \%$ and $74 \%$, respectively. In $73.5 \%$, tachycardia was observed. In patients with available laboratory values, $69 \%$ had CRP levels above $120 \mathrm{mg} / \mathrm{L}$, while leukopenia was found in one-fifth $(21 \%)$ and lymphopenia and neutropenia in $89 \%$ and $20 \%$, respectively. Half of patients had a severe anemia $(<8 \mathrm{~g} / \mathrm{dL}, 51 \%)$. Disease progression to complicated or critical phases was not associated with an active cancer disease at detection of SARS-CoV-2 ( $p$ values 0.194 and 0.718 , respectively).

Of all patients, 194 (44.5\%) patients reached the recovery phase, whereas clinical improvement or discharge was reported for a total of 292 (67.5\%) patients (Fig. 1).

\section{Survival analysis}

Kaplan-Meier estimates showed a median survival of 48 days (95\% CI 33.5-62.4) for all cancer patients and 31 days (95\% CI 22.6-39.3) for ICU patients. The primary endpoint (death related to COVID-19) was observed in 97 (22.5\%) patients, while the majority died within 30 days after diagnosis of SARS-CoV-2 (19.5\%). The mortality rate was significantly higher in male patients $(28 \%, 73 / 216$ vs $13.5 \%, 24 / 177 ; p$ value $<0.001)$ and in patients with an active cancer disease at detection of SARS-CoV-2 (26.5\%, 52/197 vs 17\%, 28/167; $p$ value 0.027 ). In solid tumors and hematological malignancies, mortality was comparable (Fig. 2). The highest death rates were seen in patients aged $76-85(31.5 \%, 50 / 158)$ and in patients $>85$ years $(37 \%, 14 / 38)$. In the age categories 56 65 years and $<55$, COVID-19-related mortality was $11 \%$ $(8 / 72)$ and $9 \%(5 / 55)$, respectively.

In the group of 119 patients treated on an ICU, 47 (39.5\%) patients died attributed to COVID-19, 37 (31\%) within 30 days after detection of SARS-CoV-2. Again, mortality was higher in males $(57.5 \%, 23 / 40$ vs $33.5 \%, 5 / 15 ; p$ value 0.103$)$ and slightly higher in patients with an active cancer disease $(50 \%, 13 / 26$ vs $43 \%, 9 / 21 ; p$ value 0.626 ). The majority of patients who died was aged $66-85(74.5 \%, 35 / 47)$. Although $28 / 38$ patients $>85$ years showed progression to severe COVID-19 phases, ICU admission was seen only in one.

Of all patients, who died attributed to COVID-19, 15 (18\%, $15 / 83$ ) patients were on palliative care before positively tested for SARS-CoV-2. In 76.5\% (66/86), treatment goals were changed from curative to palliative, mainly due to progression of COVID-19. Both were predominantly observed in patients aged 76 and older. 
Table 2 Patients' characteristics

\begin{tabular}{|c|c|c|c|}
\hline & Cancer patients, $N=435$ & Non-cancer patients, $N=2636$ & $p$ value \\
\hline \multicolumn{3}{|l|}{ Age categories; n/N (\%) } & \multirow[t]{10}{*}{$<0.001$} \\
\hline$<18$ years & $5 / 435(1)$ & $47 / 2636(2)$ & \\
\hline $18-25$ years & $1 / 435(0.5)$ & $60 / 2636(2)$ & \\
\hline $26-35$ years & $4 / 435(1)$ & $197 / 2636(7.5)$ & \\
\hline $36-45$ years & $13 / 435(3)$ & $239 / 2636(9)$ & \\
\hline $46-55$ years & $36 / 435(8)$ & $434 / 2636(16.5)$ & \\
\hline $56-65$ years & $72 / 435(16.5)$ & $527 / 2636(20)$ & \\
\hline $66-75$ years & $108 / 435(25)$ & $413 / 2636(15.5)$ & \\
\hline $76-85$ years & $158 / 435(36.5)$ & $508 / 2636(19.5)$ & \\
\hline$>85$ years & $38 / 435(8.5)$ & $211 / 2636(8)$ & \\
\hline \multicolumn{3}{|l|}{ Sex; $\mathrm{n} / \mathrm{N}(\%)$} & \multirow[t]{3}{*}{0.952} \\
\hline Female & $176 / 435(40.5)$ & $1073 / 2636(40.5)$ & \\
\hline Male & $259 / 435(59.5)$ & $1563 / 2636(59.5)$ & \\
\hline \multicolumn{4}{|l|}{$\mathrm{CCI}( \pm \mathrm{SD})$} \\
\hline CCI mean & $4.65( \pm 2.68)$ & $1.12( \pm 1.77)$ & $<0.001$ \\
\hline CCI w/o cancer & $1.59( \pm 1.99)$ & $1.12( \pm 1.77)$ & $<0.001$ \\
\hline \multicolumn{4}{|l|}{ Comorbidities; $\mathrm{n} / \mathrm{N}(\%)$} \\
\hline Hemiplegia & $15 / 431(3.5)$ & $55 / 2562(2)$ & 0.090 \\
\hline Dementia & $48 / 429(11)$ & $209 / 2358(8)$ & 0.037 \\
\hline Cerebrovascular disease, Stroke, TIA & $59 / 427(14)$ & $222 / 2560(8.5)$ & 0.001 \\
\hline Myocardial infarction & $36 / 424(8.5)$ & $156 / 2539(6)$ & 0.069 \\
\hline Chronic heart failure & $52 / 420(12)$ & $242 / 2537(9.5)$ & 0.071 \\
\hline Peripheral vascular disease & $34 / 421(8)$ & $104 / 2521(4)$ & $<0.001$ \\
\hline Hypertension & $259 / 430(60)$ & $1249 / 2591(48)$ & $<0.001$ \\
\hline Coronary artery disease & $81 / 420(19.5)$ & $343 / 2518(13.5)$ & 0.002 \\
\hline COPD & $39 / 430(9)$ & $149 / 2572(6)$ & 0.009 \\
\hline Asthma & $15 / 429(3.5)$ & $137 / 2564(5.5)$ & 0.107 \\
\hline Other chronic pulmonary disease & $27 / 422(6.5)$ & $110 / 2539(4.5)$ & 0.061 \\
\hline Connective tissue disease & $3 / 429(0.5)$ & $20 / 2560(1)$ & 0.857 \\
\hline Peptic ulcer disease & $19 / 428(4.5)$ & $51 / 2558(2)$ & 0.002 \\
\hline Chronic liver disease & $5 / 428(1)$ & $53 / 2558(2)$ & 0.210 \\
\hline Liver cirrhosis & $6 / 428(1.5)$ & $22 / 2561(1)$ & 0.281 \\
\hline Diabetes w/o end organ damage & $63 / 429(14.5)$ & $349 / 2572(13.5)$ & 0.534 \\
\hline Diabetes w end organ damage & $41 / 426(9.5)$ & $172 / 2563(6.5)$ & 0.030 \\
\hline Chronic kidney disease & $87 / 428(20.5)$ & $359 / 2569(14)$ & 0.001 \\
\hline Acute kidney injury & $25 / 328(7.5)$ & $121 / 1878(6.5)$ & 0.428 \\
\hline Organ transplantation & $5 / 429(1)$ & $49 / 2564(2)$ & 0.283 \\
\hline \multicolumn{4}{|l|}{ Obesity; n/N (\%) } \\
\hline $\mathrm{BMI}>30 \mathrm{~kg} / \mathrm{m}^{2}$ & $69 / 184(24)$ & $419 / 1597(26)$ & 0.453 \\
\hline Smoking; n/N (\%) & & & 0.044 \\
\hline Active smoking & $36 / 225(16)$ & $170 / 1270(14)$ & \\
\hline Non-smoking & $141 / 225(62.5)$ & $899 / 1270(70)$ & \\
\hline Former smoking & $48 / 225(21.5)$ & $201 / 1270(16)$ & \\
\hline \multicolumn{4}{|l|}{ Poor performance status } \\
\hline $\mathrm{ECOG}>2 ; \mathrm{n} / \mathrm{N}(\%)$ & $44 / 187(23.5)$ & & \\
\hline \multicolumn{4}{|c|}{ Underlying cancer disease (according to $\mathrm{CCI}) ; \mathrm{n} / \mathrm{N}(\%)$} \\
\hline Solid tumor & $256 / 435(59)$ & & \\
\hline Solid tumor, metastasized & $95 / 435(22)$ & & \\
\hline Lymphoma & $76 / 435(17.5)$ & & \\
\hline
\end{tabular}


Table 2 (continued)

\begin{tabular}{|c|c|c|c|}
\hline & Cancer patients, $N=435$ & Non-cancer patients, $N=2636$ & $p$ value \\
\hline Leukemia & $48 / 435(11)$ & & \\
\hline \multicolumn{4}{|c|}{ Disease status at detection of SARS-CoV-2; n/N (\%) } \\
\hline Active disease & $193 / 359(54)$ & & \\
\hline Chemotherapy & $71 / 357(20)$ & & \\
\hline High-dose steroids & $27 / 340(8)$ & & \\
\hline Targeted therapy & $48 / 341(14)$ & & \\
\hline Other immunosuppressive therapy & $36 / 343(10.5)$ & & \\
\hline Remission & $59 / 117(50.5)$ & & \\
\hline Anti-cancer therapy ( $\leq 1$ month) & $96 / 418(22)$ & & \\
\hline Chemotherapy ( $\leq 3$ months) & $36 / 418(8.5)$ & & \\
\hline Surgery ( $\leq 3$ months) & $39 / 418(9)$ & & \\
\hline Radiation ( $\leq 3$ months) & $25 / 418(5.5)$ & & \\
\hline
\end{tabular}

CCI Charlson Comorbidity Index, w/o without, BMI body mass index, ECOG Eastern Cooperative Oncology Group

In univariate analysis, male sex (Fig. 3) and advanced age ( $p$ value 0.005 ) were predictive for a worse outcome, whereas an active disease or high-dose steroids at detection of SARSCoV-2 did not influence survival significantly ( $p$ values 0.060 and 0.907 , respectively).

In order to compare clinical courses of cancer and noncancer patients, the group of cancer patients was compared to a total of 2636 non-cancer patients included into LEOSS in the same time period. Data of non-cancer patients are shown in Table 2. More men than women were included (59.5\% vs $40.5 \%$ ); most common age category was 56-65 (20\%). Mean CCI was 1.1. Comparing survival of both groups, cancer patients showed a significantly worse outcome
(Fig. 4). Thus, survival at day 30 was $77 \%$ (95\% CI $74.35-$ 79.45 ) and $70.5 \%$ (95\% CI 64.2-76.4, $p$ value 0.001 ) in noncancer and cancer patients, respectively. In patients on intensive care treatment, Kaplan-Meier estimates showed a 30-daysurvival of 56.5\% (95\% CI 51.5-62) in non-cancer and 54.5 (95\% CI 42.9-60.1, $p$ value 0.077) in cancer patients. Mortality attributed to COVID-19 was significantly higher in cancer patients $(14 \%, 367 / 2636$ vs $22.5 \%, 97 / 435 ; p$ value $<0.001$ ). Comparing baseline data of both groups, age distribution and prevalence of comorbidity differed significantly ( $p$ value $<0.001$ each, Table 2) as non-cancer patients were younger and had less comorbidities. To account for those differences, survival analysis was adjusted for age, sex, and

Fig. 1 Phases of COVID-19

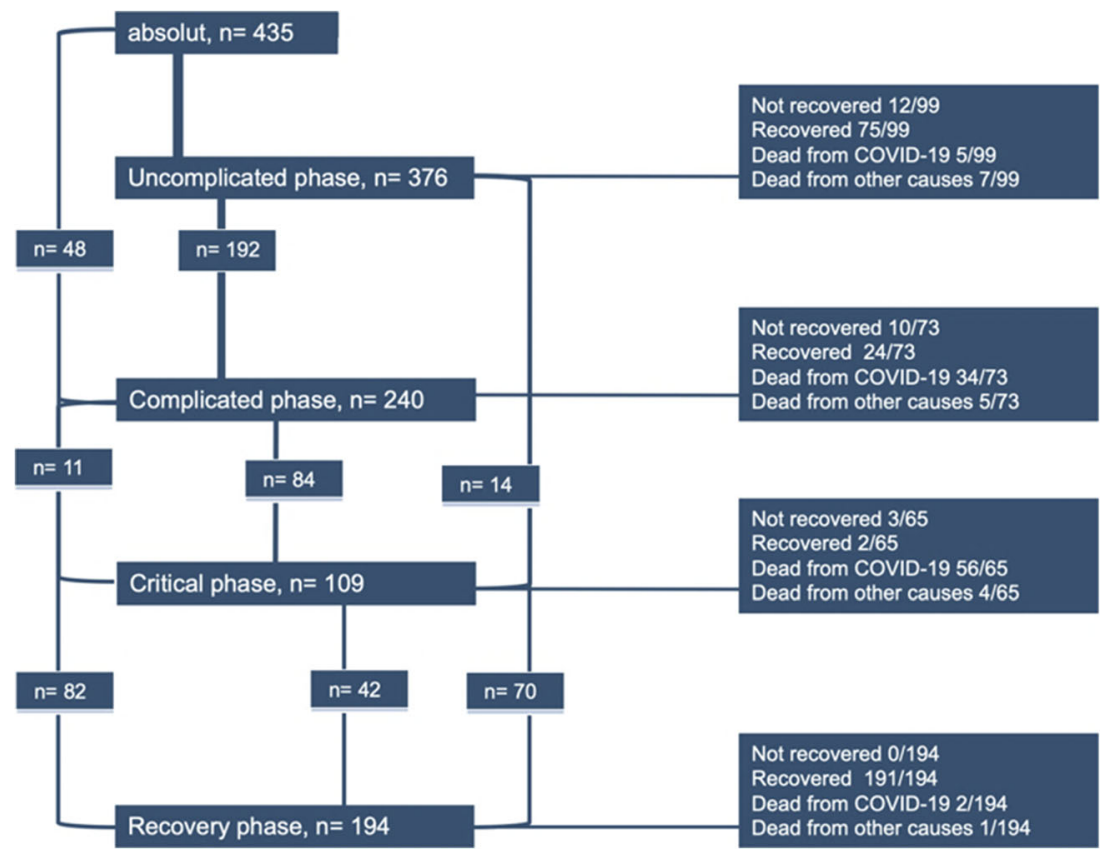


Fig. 2 Mortality rate attributed to COVID-19

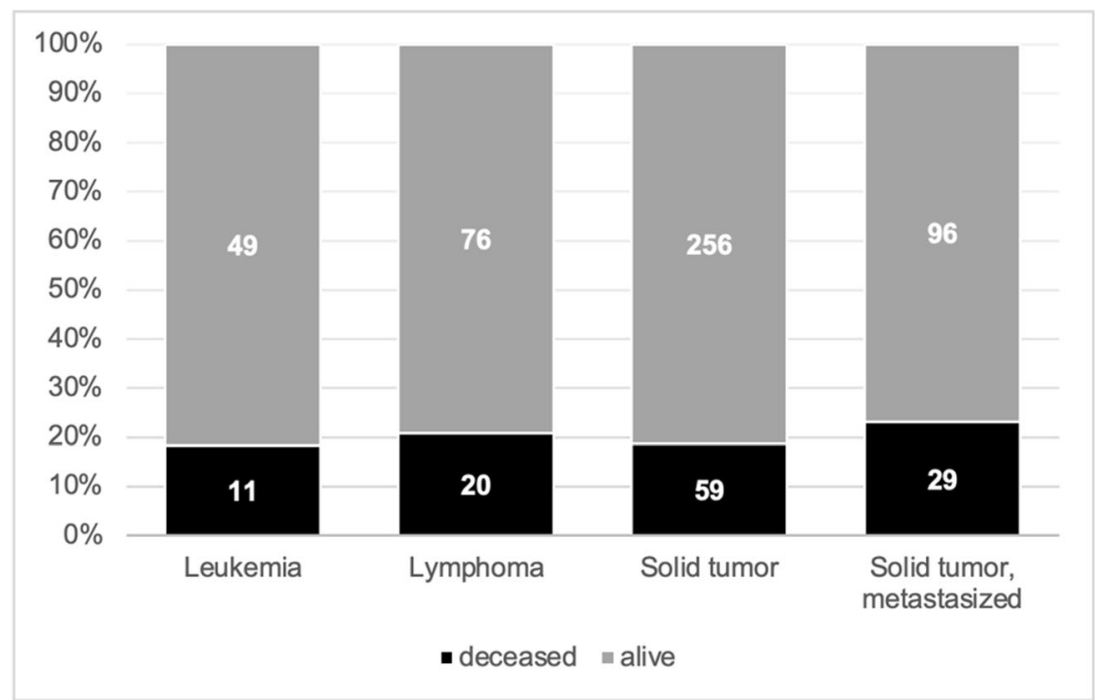

comorbidity. Four groups with almost equally distributed confounders were identified (suppl. Table 2). Across these groups, no significant differences in survival were seen except for ICU patients aged 56-65. Here, 30-day survival was 67\% (95\% CI 57.1-77.1) in non-cancer patients and $48 \%$ (95\% CI $18.4-78, p$ value 0.016 , Fig. 5) in cancer patients, respectively. Mortality rates were comparable, while highest death rates were seen in ICU patients greater than 65 and in patients greater than 85 years of age.

\section{Discussion}

This multicenter cohort study provides detailed information on epidemiological and clinical characteristics of cancer

a

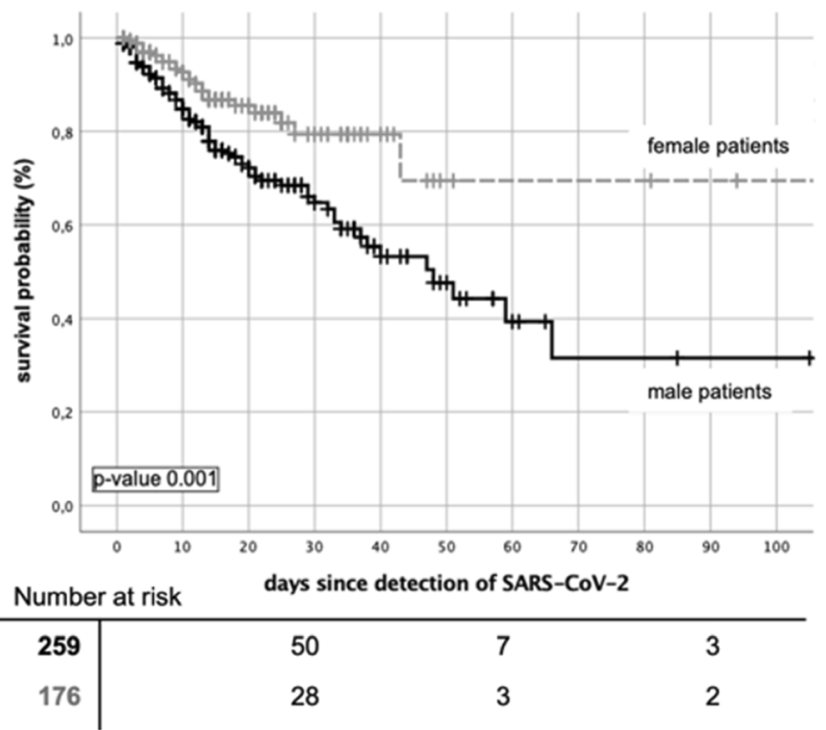

patients compared to non-cancer patients, both positively tested for SARS-CoV-2. Our cohort consisted of 435 cancer and 2636 non-cancer patients, respectively. Patients of both groups required medical care at a LEOSS study site.

LEOSS is a multicenter cohort study, which is characterized by an open and collaborative approach. By now, LEOSS registers 256 active European and non-European study sites [16]. Highest documentation rates were performed by universities and tertiary care hospitals in larger cities. As a consequence, rural areas and community practices are underrepresented causing a bias towards severe cases. Over the course of the COVID-19 pandemic, medical knowledge steadily grows. Therefore, eCRFs are regularly updated and extended. As a result, data of patients documented in the early pandemic are incomplete, and absolute numbers vary.

b

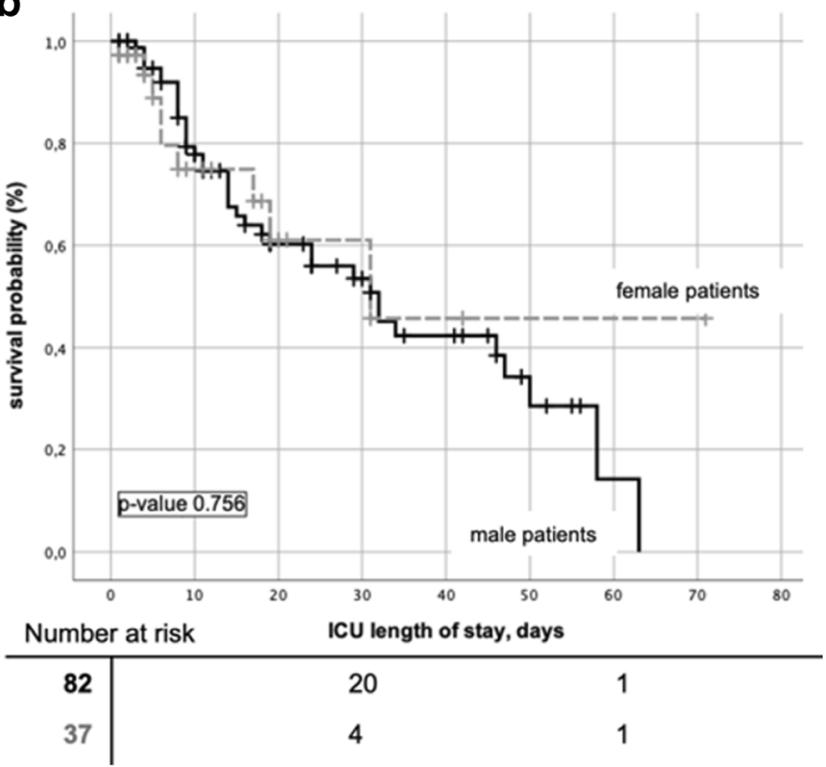

Fig. 3 Kaplan-Meier survival comparing female vs male in (a) all cancer patients and (b) cancer patients on intensive care units 

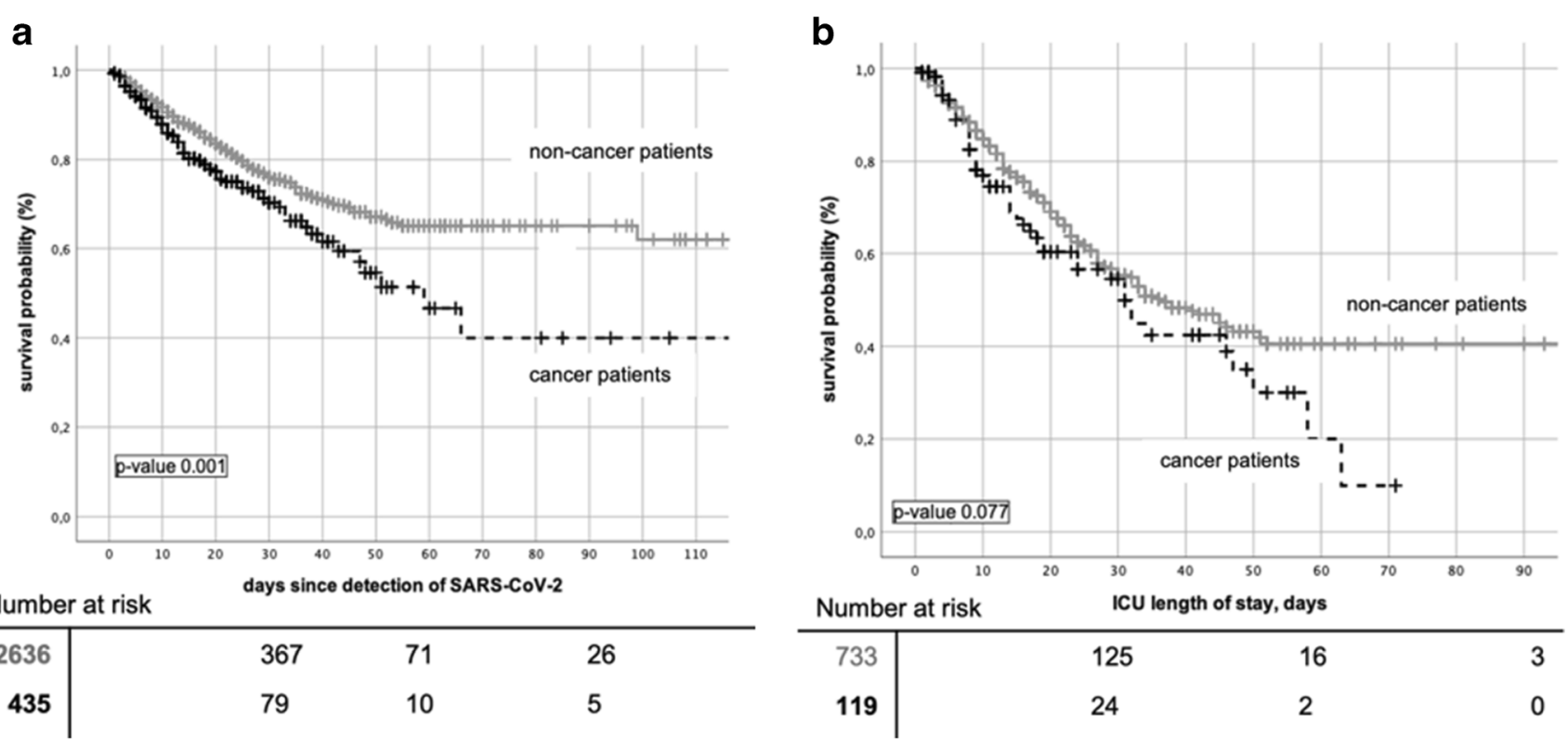

Fig. 4 Kaplan-Meier curves of overall survival comparing cancer vs non-cancer patients in (a) all patients and (b) patients on intensive care units

Since most participating sites were located in Germany, only a few patients from other countries were included, and generalizability of our results might be limited [16].

Socio-demographics and comorbidity of our cancer patients were well comparable with previously published literature. Thus, our cohort was characterized by patients aged 65 years and older and a male predominance $[5,9,12,13$, 17-19]. Commonest comorbidity was hypertension, followed by chronic kidney disease and diabetes [5, 9, 12, 14].

As reported in other studies, half of our patients had an active cancer disease, while one out of every 20 patients had received an anti-cancer treatment within 1 month before detection of SARS-CoV-2 [13, 14].

Even though solid tumors were more frequent, hematological malignancies were overrepresented compared to a nonCOVID-19 cancer cohort from the UK reporting a prevalence of $9.5 \%$ [19]. It can thus be reasonably assumed that patients with hematological malignancies are more often exposed to the healthcare environment, where thresholds for testing are lower in hospital settings. Additionally, Lee at al. reported an increased susceptibility to viral infections in patients with hematological malignancies [19].

At detection of SARS-CoV-2, most patients were in an uncomplicated phase, which was in accordance to earlier reported patient cohorts, including cancer and non-cancer patients [20, 21]. Similar to published data, anemia, lymphopenia, and elevated CRP were common findings in cancer patients $[13,17]$.

Throughout infection course, progression to complicated or critical phases was seen in half and ICU admission in one-quarter of patients. Distribution of COVID-19 severity categories matched with findings of the UK Coronavirus Cancer Monitoring Project (UKKCMP). Out of 800 mainly hospitalized cancer patients, severe or critical COVID-19 was reported in 45\%, whereas only $7 \%$ were admitted to ICU [12]. Former correlates with Dai et al. reporting severe COVID-19 in about $40 \%$ [5]. Admission to ICU varied between different studies, reporting the earlier mentioned $7 \%$ in a UK cancer cohort, $14 \%$ in a Canadian/Spain/American, and about $36 \%$ in a German cohort $[9,12,14]$. This apparent lack of correlation can be explained by differences in timeline of the pandemic and higher capacities of critical care beds in German hospitals [22]. Comparing age distribution of patients, who received intensive care, only a few patients older than 85 years of age were admitted. Notably, higher mortality rates were seen in patients of the same age not admitted to ICU, while transition to a palliative approach was common as well. Similar was reported by Lee et al., assuming that life-extending measures might have already been reduced in those patients [12].

In our cohort, COVID-19-related mortality was higher and survival worse than that observed in non-cancer patients. As expected, similar was seen in ICU patients. Mortality was in line with data published by Lee et al. reporting death rates of $28 \%$ for non-ICU patients and $41 \%$ for patients treated in intensive care units [12]. In accordance with previously published data, male sex, active disease, and advanced age were associated with higher mortality attributed to COVID-19 [9, 12, 14, 23].

Unlike data published in the earlier phase of the pandemic, both mortality and survival of cancer and non-cancer patients were comparable after adjustments for age, sex, and comorbidity. Thus, Mehta et al. reported significantly higher ageadjusted case fatality rates, while Dai et al. highlighted a severe disease course and worse outcome in 105 cancer patients compared with an age-matched non-cancer control group [5, 13]. Moreover, a Belgian analysis drew attention to patients with solid tumors having a higher in-hospital COVID-19 mortality compared to an age-, sex-, and comorbidity-adjusted 

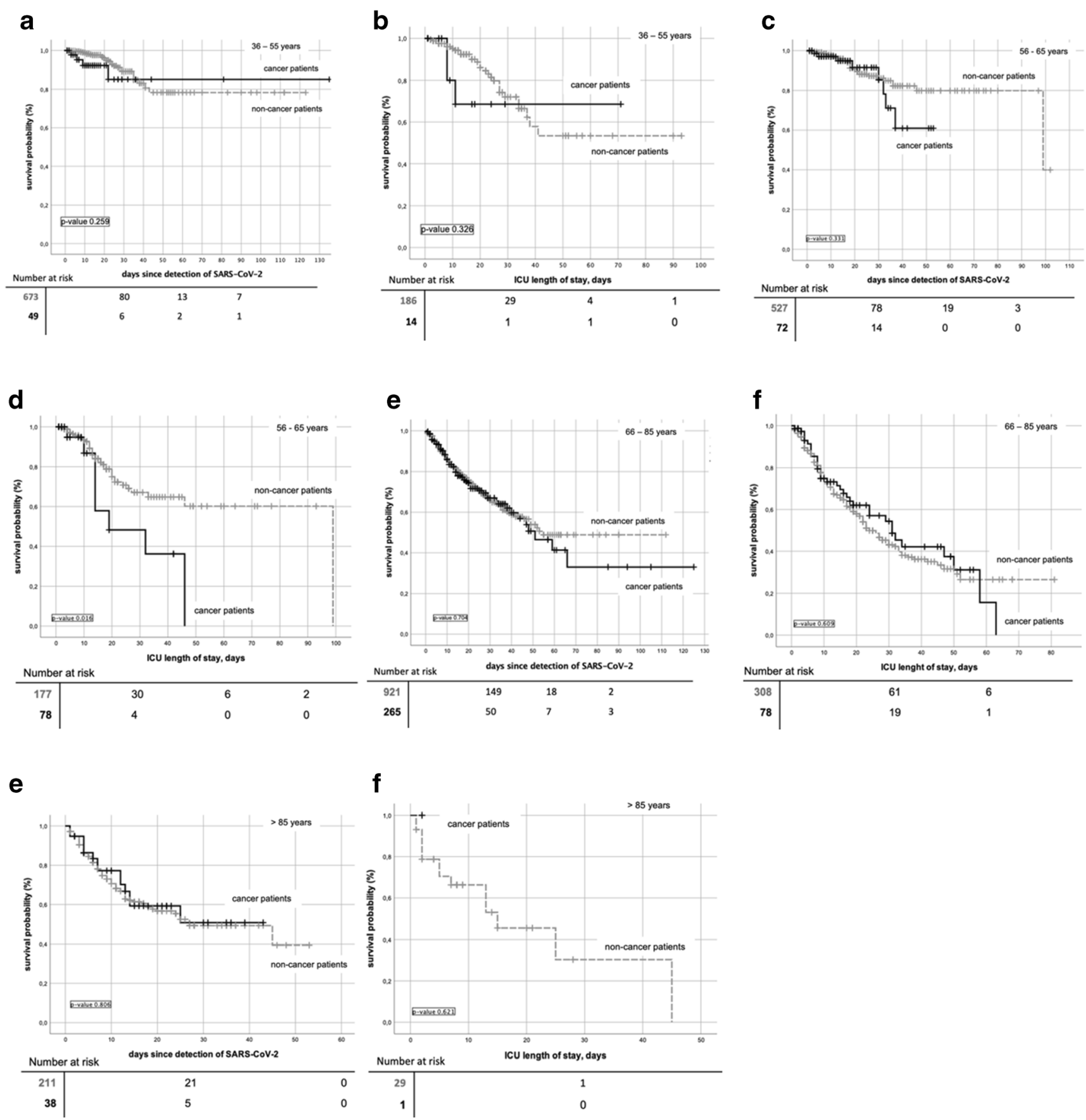

Fig. 5 Kaplan-Meier curves of overall survival for all patients and patients on ICU in (a-b) patients aged 35-55, (c-d) patients aged 56-65 patients, (e-f) patients aged $66-85$, and $(\mathbf{g}-\mathbf{h})$ patients $>85$ years of age

cohort of non-cancer patients. Notably, cancer patients younger than 60 years of age were at highest risk [24].

Beyond that, a recently published retrospective analysis of cancer patients with COVID-19 treated at a Comprehensive Cancer Center in Germany performed an age-matched analysis on 39 cancer and non-cancer patients, respectively. In both groups, distribution of comorbidity and sex were well comparable. No differences in mortality and survival were observed [14].

\section{Conclusion}

To the best of our knowledge, the present analysis is unique performing an age-, sex-, and comorbidity-adjusted comparison in a large cohort of cancer and non-cancer patients with COVID-19. Even though survival and mortality appeared to be comparable after adjustments, our results emphasize that cancer patients as a group are at higher risk due to advanced age and higher prevalence of comorbid conditions. 
Acknowledgments We express our gratitude to all study centers participating in the LEOSS registry. Study sites that contributed at least 5 per mille to the analyses of this study were as follows: Johannes Wesling Hospital Minden (Dr. med. Kai Wille), Hospital Ingolstadt (PD Dr. Dr. med. Stefan Borgmann), University Hospital rechts der Isar (Dr. med. Christoph Spinner), University Hospital Freiburg (Prof. Dr. med. Siegbert Rieg), Hospital Ernst von Bergmann (Dr. med. Lukas Tometten), University Hospital Essen (PD Dr. med. Sebastian Dolff), University Hospital Regensburg (PD Dr. med. Frank Hanses), University Hospital Jena (Dr. med. Maria Madeleine Rüthrich), University Hospital Tübingen (Prof. Dr. med. Silvio Nadalin), University Hospital Würzburg (Dr. med. Nora Isberner), University Hospital Cologne (Dr. med. Philipp Köhler), Hospital Passau (Dr. med. univ. Julia Lanznaster), Hospital Bremen-Mitte (Dr. med. Christiane Piepel), University Hospital Ulm (PD Dr. med. Beate Grüner), University Hospital Erlangen (Prof. Dr. med. Richard Strauss), University Hospital Heidelberg (Prof. Dr. med. Uta Merle), Ludwig Maximilian University Hospital Munich (Prof. Dr. med. Michael von Bergwelt-Baildon), Travel Clinic Paul-Lechler Hospital Tuebingen (Dr. med. Claudia Raichle), University Hospital Duesseldorf (Dr. med. Björn Jensen), University Hospital Frankfurt (Prof. Dr. med. Maria Vehreschild), Hospital St. Joseph-Stift Dresden (Dr. med. Lorenz Walter), University Hospital Schleswig-Holstein (Dr. med. Nadja Käding), Clinic Munich (Dr. med. Wolfgang Guggemos), Hospital Leverkusen (Dr. med. univ. Lukas Eberwein), Elbland Hospital Riesa (Dr. med. Jörg Schubert), Petrus Hospital Wuppertal (Dr. med Sven Stieglitz), Hospital Dortmund (Dr. Martin Hower), St. Josef-Hospital Bochum (Prof. Dr. med. Kerstin Hellwig), University Hospital Schleswig-Holstein - Kiel (Dr. med. Anette Friedrichs), Community Pracitice Dres. Kronawitter/Jung (Dr. med. Ursula Kronawitter), Maltese Hospital St. Franziskus-Hospital (Dr. med. Milena Milovanovic), University Hospital Saarland (Prof. Dr. Dr. Robert Bals), Municipal Hospital Karlsruhe (Dr. Christian Degenhardt), University Hospital Augsburg (Dr. med. Christoph Römmele), and RobertBosch-Hospital (Dr. med. Katja Rothfuss). This study was supported by the German Center for Infection Research (DZIF) and the Willy Robert Pitzer Foundation.

Authors' contributions JJ Vehreschild: initiation and leading of LEOSS. JJ Vehreschild, C Jacob, M Stecher, M Schons, and AY Classen: developing and maintaining LEOSS. M Stecher and C Jakob: data management and extraction. M M Rüthrich: statistical analysis, data interpretation, and manuscript preparation. $\mathrm{M}$ von Lilienfeld-Toal, $\mathrm{K}$ Wille, $\mathrm{C}$ Giessen-Jung, and G Beutel: data interpretation and critical revision of the manuscript. All authors: acquisition of data; all authors revised and approved the final version of the manuscript.

Funding Open Access funding enabled and organized by Projekt DEAL.

Data availability All data analyzed are included in this published article and its Supplementary Information files.

\section{Compliance with ethical standards}

Conflicts of interests MMR has received research funding from the Interdisciplinary Centre for Clinical Research (IZKF) Jena and honoraria from Janssen, outside the submitted work GB reports grants from German Federal Ministry of Research \& Education and Federal Ministry of Health, personal fee from Jazz Pharmaceuticals, MSD, and NewConceptOncology all outside the submitted work. FH received lecture and other honoraria from Correvio, Infectopharm, and Novartis, outside the submitted work. PK has received non-financial scientific grants from Miltenyi Biotec $\mathrm{GmbH}$, Bergisch Gladbach, Germany, and the Cologne Excellence Cluster on Cellular Stress Responses in Aging-Associated Diseases, University of Cologne, Cologne, Germany, and received lecture honoraria from or is advisor to Akademie für Infektionsmedizin e.V., Astellas Pharma, European Confederation of Medical Mycology, Gilead Sciences, GPR Academy
Ruesselsheim, MSD Sharp \& Dohme GmbH, Noxxon N.V., and University Hospital, LMU Munich outside the submitted work. MvLT has received travel grants and honoraria from Celgene, Gilead, Chugai, Janssen, Novartis, Amgen, Takeda, BMS, Medac, Oncopeptides, Merck, CDDF, Pfizer, is a consultant for Celgene, Gilead, Oncopeptides, MSD, 4DPharma, Janssen, Shionogi and received research funding from BMBF, Deutsche Jose Carreras Leukämie-Stiftung, IZKF Jena, DFG, Novartis, Gilead, Deutsche Krebshilfe, Celgene, Deutsche Forschungsgemeinschaft, outside the submitted work. All other corresponding authors declare no conflict of interest.

Ethical approval This study was performed in line with the principles of the Declaration of Helsinki. Approval for LEOSS was obtained by the applicable local ethics committees of all participating centers.

Informed consent Data were recorded anonymous, and no patientidentifying data were stored. Written patient informed consent was waived.

Open Access This article is licensed under a Creative Commons Attribution 4.0 International License, which permits use, sharing, adaptation, distribution and reproduction in any medium or format, as long as you give appropriate credit to the original author(s) and the source, provide a link to the Creative Commons licence, and indicate if changes were made. The images or other third party material in this article are included in the article's Creative Commons licence, unless indicated otherwise in a credit line to the material. If material is not included in the article's Creative Commons licence and your intended use is not permitted by statutory regulation or exceeds the permitted use, you will need to obtain permission directly from the copyright holder. To view a copy of this licence, visit http://creativecommons.org/licenses/by/4.0/.

\section{References}

1. Rothan HA, Byrareddy SN (2020) The epidemiology and pathogenesis of coronavirus disease (COVID-19) outbreak. J Autoimmun 109:102433

2. European Centre for Disease Prevention and Control, E (2020) [cited 2020 04.10.2020]; Available from: https://www.ecdc. europa.eu/en/covid-19-pandemic)

3. Wang D, Hu B, Hu C, Zhu F, Liu X, Zhang J, Wang B, Xiang H, Cheng Z, Xiong Y, Zhao Y, Li Y, Wang X, Peng Z (2020) Clinical characteristics of 138 hospitalized patients with 2019 novel coronavirus-infected pneumonia in Wuhan, China. JAMA 323(11):1061-1069

4. Yang X, Yu Y, Xu J, Shu H, Xia J', Liu H, Wu Y, Zhang L, Yu Z, Fang M, Yu T, Wang Y, Pan S, Zou X, Yuan S, Shang Y (2020) Clinical course and outcomes of critically ill patients with SARSCoV-2 pneumonia in Wuhan, China: a single-centered, retrospective, observational study. Lancet Respir Med 8(5):475-481

5. Dai M, Liu D, Liu M, Zhou F, Li G, Chen Z, Zhang Z, You H, Wu M, Zheng Q, Xiong Y, Xiong H, Wang C, Chen C, Xiong F, Zhang Y, Peng Y, Ge S, Zhen B, Yu T, Wang L, Wang H, Liu Y, Chen Y, Mei J, Gao X, Li Z, Gan L, He C, Li Z, Shi Y, Qi Y, Yang J, Tenen DG, Chai L, Mucci LA, Santillana M, Cai H (2020) Patients with cancer appear more vulnerable to SARS-CoV-2: a multicenter study during the COVID-19 outbreak. Cancer Discov 10(6):783-791

6. Guan WJ, Liang WH, Zhao Y, Liang HR, Chen ZS, Li YM, Liu XQ, Chen RC, Tang CL, Wang T, Ou CQ, Li L, Chen PY, Sang L, Wang W, Li JF, Li CC, Ou LM, Cheng B, Xiong S, Ni ZY, Xiang J, Hu Y, Liu L, Shan H, Lei CL, Peng YX, Wei L, Liu Y, Hu YH, Peng P, Wang JM, Liu JY, Chen Z, Li G, Zheng ZJ, Qiu SQ, Luo J, Ye CJ, Zhu SY, Cheng LL, Ye F, Li SY, Zheng JP, Zhang NF, Zhong NS, He JX; China Medical Treatment Expert Group for COVID-19 
(2020) Comorbidity and its impact on 1590 patients with COVID-19 in China: a nationwide analysis. Eur Respir J 55(5):2000547

7. Liang W, Guan W, Chen R, Wang W, Li J, Xu K, Li C, Ai Q, Lu W, Liang H, Li S, He J (2020) Cancer patients in SARS-CoV-2 infection: a nationwide analysis in China. Lancet Oncol 21(3):335-337

8. He W, Chen L, Chen L, Yuan G, Fang Y, Chen W, Wu D, Liang B, Lu X, Ma Y, Li L, Wang H, Chen Z, Li Q, Gale RP (2020) COVID19 in persons with haematological cancers. Leukemia 34(6):16371645

9. Kuderer NM, Choueiri TK, Shah DP, Shyr Y, Rubinstein SM, Rivera DR, Shete S, Hsu CY, Desai A, de Lima Lopes G Jr, Grivas P, Painter CA, Peters S, Thompson MA, Bakouny Z, Batist G, Bekaii-Saab T, Bilen MA, Bouganim N, Larroya MB, Castellano D, del Prete SA, Doroshow DB, Egan PC, Elkrief A, Farmakiotis D, Flora D, Galsky MD, Glover MJ, Griffiths EA, Gulati AP, Gupta S, Hafez N, Halfdanarson TR, Hawley JE, Hsu E, Kasi A, Khaki AR, Lemmon CA, Lewis C, Logan B, Masters T, McKay RR, Mesa RA, Morgans AK, Mulcahy MF, Panagiotou OA, Peddi P, Pennell NA, Reynolds K, Rosen LR, Rosovsky R, Salazar M, Schmidt A, Shah SA, Shaya JA, Steinharter J, Stockerl-Goldstein KE, Subbiah S, Vinh DC, Wehbe FH, Weissmann LB, Wu JTY, Wulff-Burchfield E, Xie Z, Yeh A, Yu PP, Zhou AY, Zubiri L, Mishra S, Lyman GH, Rini BI, Warner JL, Abidi M, Acoba JD, Agarwal N, Ahmad S, Ajmera A, Altman J, Angevine AH, Azad N, Bar MH, Bardia A, Barnholtz-Sloan J, Barrow B, Bashir B, Belenkaya R, Berg S, Bernicker EH, Bestvina C, Bishnoi R, Boland G, Bonnen M, Bouchard G, Bowles DW, Busser F, Cabal A, Caimi P, Carducci T, Casulo C, Chen JL, Clement JM, Chism D, Cook E, Curran C, Daher A, Dailey M, Dahiya S, Deeken J, Demetri GD, DiLullo S, Duma N, Elias R, Faller B, Fecher LA, Feldman LE, Friese CR, Fu P, Fu J, Futreal A, Gainor J, Garcia J, Gill DM, Gillaspie EA, Giordano A, Glace (M)G, Grothey A, Gulati S, Gurley M, Halmos B, Herbst R, Hershman D, Hoskins K, Jain RK, Jabbour S, Jha A, Johnson DB, Joshi M, Kelleher K, Kharofa J, Khan H, Knoble J, Koshkin VS, Kulkarni AA, Lammers PE, Leighton JC Jr, Lewis MA, Li X, Li A, Lo KMS, Loaiza-Bonilla A, LoRusso P, Low CA, Lustberg MB, Mahadevan D, Mansoor AH, Marcum M, Markham MJ, Handy Marshall C, Mashru SH, Matar S, McNair C, McWeeney S, Mehnert JM, Menendez A, Menon H, Messmer M, Monahan R, Mushtaq S, Nagaraj G, Nagle S, Naidoo J, Nakayama JM, Narayan V, Nelson HH, Nemecek ER, Nguyen R, Nuzzo PV, Oberstein PE, Olszewski AJ, Owenby S, Pasquinelli MM, Philip J, Prabhakaran S, Puc M, Ramirez A, Rathmann J, Revankar SG, Rho YS, Rhodes TD, Rice RL, Riely GJ, Riess J, Rink C, Robilotti EV, Rosenstein L, Routy B, Rovito MA, Saif MW, Sanyal A, Schapira L, Schwartz C, Serrano O, Shah M, Shah C, Shaw G, Shergill A, Shouse G, Soares HP, Solorzano CC, Srivastava PK, Stauffer K, Stover DG, Stratton J, Stratton C, Subbiah V, Tamimi R, Tannir NM, Topaloglu U, van Allen E, van Loon S, Vega-Luna K, Venepalli N, Verma AK, Vikas $\mathrm{P}$, Wall S, Weinstein PL, Weiss M, Wise-Draper T, Wood WA, Xu W(V), Yackzan S, Zacks R, Zhang T, Zimmer AJ, West J (2020) Clinical impact of COVID-19 on patients with cancer (CCC19): a cohort study. Lancet 395(10241):1907-1918

10. Park R, Chidharla A, Mehta K, Sun W, Wulff-Burchfield E, Kasi A (2020) Sex-bias in COVID-19-associated illness severity and mortality in cancer patients: a systematic review and meta-analysis. EClinicalMedicine 26:100519

11. Sanyaolu A, Okorie C, Marinkovic A, Patidar R, Younis K, Desai P, Hosein Z, Padda I, Mangat J, Altaf M (2020) Comorbidity and its impact on patients with COVID-19. SN Compr Clin Med 2(30):1-8

12. Lee LY, Cazier JB, Angelis V, Arnold R, Bisht V, Campton NA, Chackathayil J, Cheng VW, Curley HM, Fittall MW, FreemanMills L, Gennatas S, Goel A, Hartley S, Hughes DJ, Kerr D, Lee AJ, Lee RJ, McGrath S, Middleton CP, Murugaesu N, NewsomDavis T, Okines AF, Olsson-Brown AC, Palles C, Pan Y, Pettengell R, Powles T, Protheroe EA, Purshouse K, SharmaOates A, Sivakumar S, Smith AJ, Starkey T, Turnbull CD, Várnai
C, Yousaf N, UK Coronavirus Monitoring Project Team, Kerr R, Middleton G (2020) COVID-19 mortality in patients with cancer on chemotherapy or other anticancer treatments: a prospective cohort study. Lancet 395(10241):1919-1926

13. Mehta V, Goel S, Kabarriti R, Cole D, Goldfinger M, AcunaVillaorduna A, Pradhan K, Thota R, Reissman S, Sparano JA, Gartrell BA, Smith RV, Ohri N, Garg M, Racine AD, Kalnicki S, Perez-Soler R, Halmos B, Verma A (2020) Case fatality rate of cancer patients with COVID-19 in a New York Hospital System. Cancer Discov 10(7):935-941

14. Shoumariyeh K, Biavasco F, Ihorst G, Rieg S, Nieters A, Kern WV, Miething C, Duyster J, Engelhardt M, Bertz H (2020) Covid-19 in patients with hematological and solid cancers at a Comprehensive Cancer Center in Germany. Cancer Med. https://doi.org/10.1002/ cam 4.3460

15. Joharatnam-Hogan N, Khan K (2020) COVID-19 cancer conundrum-evidence driving decisions or the lack of it? BMC Med 18(1):182

16. Vehreschild JJ, Stecher M, Schons M (2020) [cited 2020 04.10.2020]; Available from: https://leoss.net

17. Zhang L, Zhu F, Xie L, Wang C, Wang J, Chen R, Jia P, Guan HQ, Peng L, Chen Y, Peng P, Zhang P, Chu Q, Shen Q, Wang Y, Xu SY, Zhao JP, Zhou M (2020) Clinical characteristics of COVID-19infected cancer patients: a retrospective case study in three hospitals within Wuhan, China. Ann Oncol 31(7):894-901

18. Engelhardt M, Shoumariyeh K, Rösner A, Ihorst G, Biavasco F, Meckel K, von Metzler I, Theurich S, Hebart H, Grube M, Kull M, Bassermann F, Schäfer-Eckart K, Hoferer A, Einsele H, Rasche L, Wäsch R (2020) Clinical characteristics and outcome of multiple myeloma patients with concomitant COVID-19 at Comprehensive Cancer Centers in Germany. Haematologica. https://doi.org/10.3324/haematol. 2020.262758

19. Lee LYW, Cazier JB, Starkey T, Briggs SEW, Arnold R, Bisht V, Booth S, Campton NA, Cheng VWT, Collins G, Curley HM, Earwaker P, Fittall MW, Gennatas S, Goel A, Hartley S, Hughes DJ, Kerr D, Lee AJX, Lee RJ, Lee SM, Mckenzie H, Middleton CP, Murugaesu N, Newsom-Davis T, Olsson-Brown AC, Palles C, Powles T, Protheroe EA, Purshouse K, Sharma-Oates A, Sivakumar S, Smith AJ, Topping O, Turnbull CD, Várnai C, Briggs ADM, Middleton G, Kerr R; UK Coronavirus Cancer Monitoring Project Team (2020) COVID-19 prevalence and mortality in patients with cancer and the effect of primary tumour subtype and patient demographics: a prospective cohort study. Lancet Oncol 21(10):1309-1316

20. Richardson S, Hirsch JS, Narasimhan M, Crawford JM, McGinn T, Davidson KW, and the Northwell COVID-19 Research Consortium, Barnaby DP, Becker LB, Chelico JD, Cohen SL, Cookingham J, Coppa K, Diefenbach MA, Dominello AJ, DuerHefele J, Falzon L, Gitlin J, Hajizadeh N, Harvin TG, Hirschwerk DA, Kim EJ, Kozel ZM, Marrast LM, Mogavero JN, Osorio GA, Qiu M, Zanos TP (2020) Presenting characteristics, comorbidities, and outcomes among 5700 patients hospitalized with COVID-19 in the New York City Area. JAMA 323:2052-2059

21. Jakob CEM, Borgmann S, Duygu F, Behrends U, Hower M, Merle U, Friedrichs A, Tometten L, Hanses F, Jung N, Rieg S, Wille K, Grüner B, Klinker H, Gersbacher-Runge N, Hellwig K, Eberwein L, Dolff S, Rauschning D, von Bergwelt-Baildon M, Lanznaster J, Strauß R, Trauth J, de With K, Ruethrich M, Lueck C, Nattermann J, Tscharntke L, Pilgram L, Fuhrmann S, Classen A, Stecher M, Schons M, Spinner C, Vehreschild JJ (2020) First results of the "Lean European Open Survey on SARS-CoV-2-Infected Patients (LEOSS)". Infection. https://doi.org/10.1007/s15010-020-01499-0

22. Rhodes A, Ferdinande P, Flaatten H, Guidet B, Metnitz PG, Moreno RP (2012) The variability of critical care bed numbers in Europe. Intensive Care Med 38(10):1647-1653 
23. Tian J, Yuan X, Xiao J, Zhong Q, Yang C, Liu B, Cai Y, Lu Z, Wang J, Wang Y, Liu S, Cheng B, Wang J, Zhang M, Wang L, Niu S, Yao Z, Deng X, Zhou F, Wei W, Li Q, Chen X, Chen W, Yang Q, Wu S, Fan J, Shu B, Hu Z, Wang S, Yang XP, Liu W, Miao X, Wang Z (2020) Clinical characteristics and risk factors associated with COVID-19 disease severity in patients with cancer in Wuhan, China: a multicentre, retrospective, cohort study. Lancet Oncol 21(7):893-903

24. de Azambuja E, Brandão M, Wildiers H, Laenen A, Aspeslagh S, Fontaine C, Collignon J, Lybaert W, Verheezen J, Rutten A, Vuylsteke P, Goeminne JC, Demey W, van Beckhoven D,
Deblonde J, Rottey S, Geukens T, Punie K, Belgian Collaborative Group on COVID-19 Hospital Surveillance and the Belgian Society of Medical Oncology (BSMO) (2020) Impact of solid cancer on in-hospital mortality overall and among different subgroups of patients with COVID-19: a nationwide, population-based analysis. ESMO Open 5(5):e000947

Publisher's note Springer Nature remains neutral with regard to jurisdictional claims in published maps and institutional affiliations.

\section{Affiliations}

Maria Madeleine Rüthrich ${ }^{1,2}$ (D) $\cdot$ C. Giessen-Jung ${ }^{3} \cdot$ S. Borgmann ${ }^{4} \cdot$ A. Y. Classen ${ }^{5,6} \cdot$ S. Dolff $^{7} \cdot$ B. Grüner $^{8} \cdot$ F. Hanses $^{9}$ • N. Isberner ${ }^{10} \cdot$ P. Köhler ${ }^{11} \cdot$ J. Lanznaster ${ }^{12} \cdot$ U. Merle ${ }^{13} \cdot$ S. Nadalin ${ }^{14} \cdot$ C. Piepel $^{15} \cdot$ J. Schneider $^{16,17} \cdot$ M. Schons $^{5} \cdot$

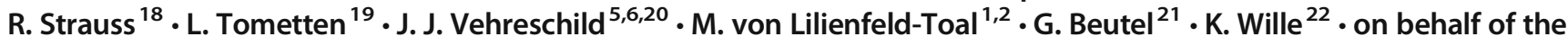
LEOSS Study Group

1 Department of Internal Medicine II, Hematology and Medical Oncology, University Hospital Jena, Am Klinikum 1, 07747 Jena, Germany

2 Leibniz Institute for Natural Product Research and Infection Biology, Hans-Knöll Institute, Jena, Germany

3 Department of Internal Medicine III, Ludwig Maximilian University, Munich, Germany

4 Department of Infectious Diseases and Infection Control, Ingolstadt Hospital, Ingolstadt, Germany

5 Department I for Internal Medicine, University of Cologne, Faculty of Medicine and University Hospital Cologne, Cologne, Germany

6 German Centre for Infection Research (DZIF), partner site BonnCologne, Cologne, Germany

7 Department of Infectious Diseases, University Hospital Essen, University Duisburg Essen, Essen, Germany

8 Section Clinical Infectiology, University Hospital Ulm, Ulm, Germany

9 Emergency Department, University Hospital Regensburg, Regensburg, Germany

10 Department of Internal Medicine II, Division of Infectious Diseases, University Hospital Würzburg, Würzburg, Germany

11 Cologne Excellence Cluster on Cellular Stress Responses in AgingAssociated Diseases (CECAD), University of Cologne, Cologne, Germany
12 Department of Internal Medicine II, Passau Hospital, Passau, Germany

13 Department of Internal Medicine IV, University Hospital Heidelberg, Heidelberg, Germany

14 Department of General, Visceral and Transplant Surgery, University Hospital Tübingen, Tübingen, Germany

15 Hospital Bremen-Center, Bremen, Germany

16 Department of Internal Medicine II, Technical University of Munich, School of Medicine, University hospital rechts der Isar, Munich, Germany

17 Cologne Excellence Cluster on Cellular Stress Responses in AgingAssociated Diseases (CECAD), University of Cologne, Cologne, Germany

18 Medical Clinic I, University Hospital Erlangen, Erlangen, Germany

19 Department of Gastroenterology and Infectiology, Hospital Ernstvon-Bergmann, Potsdam, Germany

20 Department of Internal Medicine, Hematology/Oncology, Goethe University Frankfurt, Frankfurt am Main, Germany

21 Department of Hematology, Hemostasis, Oncology and Stem Cell Transplantation, Hannover Medical School, Hannover, Germany

22 University of Bochum, University Clinic for Hematology, Oncology, Hemostaseology and Palliative Care, Minden, Germany 